\title{
ORIGINAL
}

\section{VALOR NUTRITIVO DA BIOMASSA DE CÉLULAS ÍNTEGRAS, DO AUTOLISADO E DO EXTRATO DE LEVEDURA ORIGINÁRIA DE CERVEJARIA}

\author{
NUTRITIVE VALUE OF BIOMASS OF INTEGRAL CELLS, AUTOLISATE \\ AND EXTRACT AND YEAST CELLS FROM BEER
}

\author{
Elke Simone Dias VILELA' \\ Valdemiro Carlos SGARBIERI' \\ Izabela Dutra ALVIM'
}

\begin{abstract}
RESUMO
Esta pesquisa teve como principal objetivo verificar a capacidade da levedura e seus derivados, autolisado e extrato, em manter o crescimento de ratos recém-desmamados, quando usados em substituição parcial a uma dieta-padrão ideal. Usou-se substituição de 10, 20 ou 30\% da dieta-padrão recomendada pelo American Institute of Nutrition - 93G, por uma mistura (amido de milho + produto de levedura + óleo de soja), mantendo as dietas modificadas isoprotéicas (20\% proteína) e isocalóricas. Com as substituições, os produtos de levedura participaram das dietas nas concentrações de 4, 8 ou 12\%, respectivamente. As dietas substituídas, contendo diferentes proporções de produtos de levedura, provocaram crescimento dos ratos igual ou superior ao da dieta-padrão. O ritmo de crescimento foi proporcional ao aumento da participação dos produtos de levedura. Os índices séricos de ácido úrico, uréia e atividade de transaminases não revelaram sintomas de intoxicação pelo uso dos produtos de levedura.
\end{abstract}

Termos de indexação: Saccharomyces cerevisiae, células íntegras, autolisado, extrato, valor nutritivo.

\begin{abstract}
The main objective of this research was to check on the capacity of yeast cells and its derivatives, autolisate and extract, to sustain weaning rats growth, when part of a standard diet for rat growth American Institute of Nutrition-93G was replaced 10, 20 or 30\% in proportion of by a mixture (corn starch + yeast product + soy oil) to maintain the substituted diets isoproteic (20\% protein) and isocaloric. In the modified diets, the yeast products participate in the diets in concentrations of 4 , 8 and $12 \%$, respectively. The diets containing different proportions of yeast product promoted equal or better growth than the standard diet. The growth rate of the rats augmented proportionally to the increase of yeast products in the diets. Blood serum determination of uric acid, urea and transaminases activities showed no evidences of intoxication symptoms by the ingestion of yeast products.
\end{abstract}

Index terms: Saccharomyces cerevisiae, integral cells, autolisate, extract, nutritive value.

\footnotetext{
(1) Instituto de Tecnologia de Alimentos, Centro de Química de Alimentos e Nutrição Aplicada. Av. Brasil, 2880, 13073-001, Campinas, SP, Brasil. Correspondência para/ Correspondence to: V.C.SGARBIERI.
} 


\section{INTRODUÇÃO}

Biomassa formada de células íntegras de levedura, autolisado e extrato de levedura, têm sido largamente utilizados como suplemento nutritivo e flavorizante em suas diversas formas.

A biomassa de células íntegras, inativadas, tem sido usada: a) como complemento nutritivo na formulação de alimentos saudáveis (Dziezak, 1987; Halász, 1988); b) como complemento flavorizante e funcional, em produtos como macarrão (McCormick, 1975), no enriquecimento de pães (Ching-Ming et al., 1986), em produtos tipo snacks (Bostian, et al., 1978; Stewart \& Gilliand, 1979), massa para pizza (Kamel et al., 1979), adição em salsichas e almôndegas (Junilla et al., 1981).

Segundo Alian et al. (1983a,b), a adição, no pão, de $5 \%$ de levedura de cerveja desamargada, à farinha de trigo com 70 e $90 \%$ de extração, elevou o valor biológico (BV) da proteína da massa de $31 \%$ para $76 \%$.

A biomassa de levedura exerce uma ação antioxidante, prolongando a vida-de-prateleira de alguns sistemas alimentares, quando estocados à temperatura de refrigeração ou congelamento, particularmente em sistemas ricos em gorduras insaturadas (Shackelford \& Murray, 1980).

Autolisados e extratos de levedura encontram vasta aplicação na indústria de alimentos, como na fabricação de salsichas (Parks et al., 1986); em produtos cárneos, antes do congelamento, para prevenir oxidação de lipídios e perda da solubilidade das proteínas cárnicas, durante o armazenamento no estado congelado (Anon, 1981; Lásztity, 1987); produtos como salsichas, presuntos, molhos, sopas, snacks têm sido formulados com a adição de extratos e autolisados de levedura, com uma sensível melhoria de suas propriedades sensoriais, em que o gosto à carne é realçado (Sommer, 1983; Schmidt, 1987).

Recentemente, tem havido uma forte tendência de explorar comercialmente leveduras, através do isolamento de alguns de seus principais constituintes como enzimas (invertase, lactase) nucleotídios, proteínas (manoproteínas), polissacarídeos (glicana, manana), além de lipídios, como fosfolipídios e ergosterol (Cameron et al., 1988; Kollar et al., 1992; Belem \& Lee, 1997; Belem \& Lee, 1998). Esses componentes, quando isolados, apresentam propriedades específicas de grande interesse em Ciência de Alimentos e em Nutrição.

Neste trabalho, estudou-se o valor nutritivo global de células íntegras, do autolisado e do extrato levedura, quando utilizados em diferentes proporções, em substituição a uma dieta completa para ratos em crescimento, avaliando-se os efeitos da substituição no ritmo de crescimento, nos índices sangüíneos de uréia, ácido úrico e atividade das transminases (TGO e TGP) e no estado geral de saúde dos animais.

\section{MATERIAL E MÉTODOS}

\section{Material}

Levedura (Saccharomyces sp.) proveniente de cervejarias cedida pela empresa Produtos Especiais para Alimentos (PRODESA), na forma de suspensão com aproximadamente $20 \%$ de sólidos, em base seca.

\section{Métodos}

Processamento da biomassa: a suspensão de células foi, inicialmente, submetida a tratamentos, em planta piloto, para coleta de células por centrifugação e desamargamento. Após centrifugação, a biomassa foi tratada com solução a $0,2 \%$ de $\mathrm{NaOH}(1: 1, p / v)$, seguida de nova centrifugação e lavagens com água para eliminação do hidróxido de sódio.

A biomassa desamargada foi submetida à autólise (24h, $55^{\circ} \mathrm{C}$, suspensão a $20 \%$ de células) em fermentador Newbrunswick de 250 L, seguindo-se a pasteurização $\left(85^{\circ} \mathrm{C}, 15 \mathrm{~min}\right)$ e centrifugação. As frações (solúvel e insolúvel) foram separadas por centrifugação e denominadas extrato bruto e parede celular, respectivamente. O extrato bruto foi submetido à clarificação (centrifugação), concentração (vácuo) e desidratação em spray dryer. Parte do autolisado total e da biomassa de células íntegras e desamargadas, também foi desidratada em spray, obtendo-se os seguintes materiais, na forma desidratada: células íntegras de levedura (LI); autolisado total de levedura (AT) e extrato de levedura (Ex).

\section{Métodos analíticos}

Composição centesimal: os teores de proteína $(\mathrm{N} \times 5,8)$, de umidade e de cinzas foram determinados seguindo os procedimentos descritos pela Association of Official Analytical Chemists (Association..., 1990); lipídios totais, pelo método de Bligh \& Dyer (1959); fibra alimentar (solúvel e insolúvel), pelo método de Asp et al. (1983); ácido nucléico (RNA) foi determinado pelo método de Hebert et al. (1971).

\section{Ensaio com ratos}

O valor nutritivo da biomassa formada de células íntegras, do autolisado e extrato de levedura foi estudado através da substituição de quantidades crescentes da dieta recomendada pelo American Institute of Nutrition (AIN-93G) para ratos em crescimento, segundo Reeves et al. (1993). 
Para a realização do ensaio, foram preparadas 10 dietas: uma dieta-padrão, elaborada conforme AIN-93G, recomendada para ratos em crescimento, contendo $20 \%$ de proteína, proveniente de uma caseína comercial (85\% de proteína); nove grupos, em que se fez substituições de 10, 20 ou 30\% da dieta-padrão, por misturas contendo (amido de milho + produto de levedura + óleo de soja). Essas misturas foram preparadas antes das substituições, para que se pudessem manter a dieta-padrão e as dietas substituídas, isoprotéicas (20\% de proteína) e isocalóricas. Os níveis reais de produtos de levedura, nas dietas substituídas foram de 4, 8 e 12\% para 10, 20 e 30\% de substituição da dieta-padrão, respectivamente.

Foram utilizados 150 ratos machos da linhagem Wistar, livres de patógenos específicos (SPF), provenientes do Centro de Animais de Laboratório da Unicamp. Os animais, com 28 dias de idade no início do experimento, foram distribuídos em 10 grupos de 15 ratos, que foram alojados em gaiolas individuais e mantidos no laboratório de experimentação a $21 \pm$ $2^{\circ} \mathrm{C}$, com alternância claro-escuro de $12 \mathrm{~h}$. Cada grupo de 15 ratos recebeu um dos seguintes tipos de dieta e água ad libitum: dieta-padrão, com 20\% de caseína (CAS); dietas contendo biomassa de levedura íntegra (LI), com 10, 20 ou 30\% de substituição (LI 10, LI 20 ou LI 30\%); dietas contendo autolisado de levedura (AT), com 10, 20 ou 30\% de substituição (AT 10, AT 20 ou AT $30 \%$ ); dietas contendo extrato de levedura (Ex), com 10, 20 ou 30\% de substituição (Ex 10, Ex 20 ou Ex 30\%) (Figura 1).

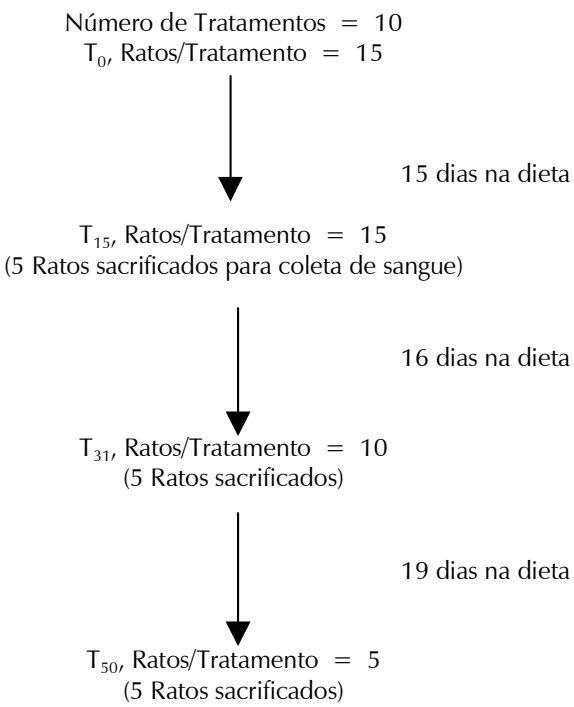

$\mathrm{T}_{0}=$ tempo zero (início).

$\mathrm{T}_{15}, \mathrm{~T}_{31}$ e $\mathrm{T}_{50}$, respectivamente 15,31 , ou 50 dias após o início do experimento.

Figura 1. Organograma geral de execução dos experimentos.

\section{Análise estatística}

Para a análise estatística, utilizou-se o programa STACTISTICA/w 5.01, aplicando-se análise de variância (ANOVA) e teste de média $(\mathrm{p}<0,05)$ pelo teste " $\mathrm{t}$ " de Tukey (Stactistica..., 1995).

\section{RESULTADOS E DISCUSSÃO}

Os componentes que aparecem em maior concentração nas células íntegras (LI) e no autolisado (AT) são as proteínas, seguidas da fibra solúvel, de substância minerais e do RNA. No extrato (Ex), pela quase ausência de fibra, predominaram as proteínas, as substâncias minerais e os componentes não determinados, provavelmente com predominância de açúcares solúveis, incluindo oligossacarídeos que não precipitaram em etanol, utilizado para precipitar a fibra solúvel (Tabela 1).

Esse resultado de composição centesimal se aproxima muito de dados já descritos na literatura (Guzmán-Juarez, 1983; Halász \& Lásztity, 1991).

Tabela 1. Composição centesimal da biomassa de levedura formada de células íntegras (LI), autolisado (AT) e extrato de levedura (Ex).

\begin{tabular}{lrrr}
\hline \multirow{2}{*}{ Componente } & \multicolumn{3}{c}{ Produtos } \\
\cline { 2 - 4 } & \multicolumn{3}{c}{ AT } \\
\hline
\end{tabular}

*Nãodeterminado

Os resultados relativos ao consumo de dietas, ingestão de proteínas, ganho de peso e PER operacional $\left(\mathrm{PER}_{\mathrm{op}}\right)$ dos ratos nas várias dietas, com 20\% de proteína, estão expressos na Tabela 2. Não houve diferença estatística para os vários tratamentos, em todos os índices determinados. Deve-se notar que o PER op encontrado $(\sim 1,5)$ é bem inferior ao PER encontrado na literatura para a caseína, quando determinado com ratos de 21 dias de idade, utilizando dieta com $10 \%$ de caseína (Halász \& Lásztity, 1991; Pacheco et al., 1997). Tanto a idade como a concentração de proteínas na dieta influi no valor de PER. Este índice diminui com a idade do rato e com o aumento da concentração de proteína, acima do nível de manutenção do rato, que é de aproximadamente $6 \%$ para a caseína (Sgarbieri, 1996). 
Tabela 2. Consumo de dietas, ingestão de proteínas e variação de pesos em ratos submetidos à dieta-padrão (20\% de caseína) e dietas em que 10, 20 e 30\% da dieta-padrão foi substituída por misturas contendo, respectivamente, 4,8 ou 12\% de produto de levedura.

\begin{tabular}{|c|c|c|c|c|}
\hline Tratamentos* & $\begin{array}{l}\text { Dieta ingerida } \\
(\mathrm{g})\end{array}$ & $\begin{array}{c}\text { Proteína ingerida } \\
\text { (g) }\end{array}$ & Ganho de peso & $\begin{array}{c}\text { PER }_{\text {op }} \\
\text { (28 dias) }\end{array}$ \\
\hline CAS (\%) & $474,05 \pm 39,39$ & $94,81 \pm$ & $141,65 \pm$ & $1,50 \pm 0,07$ \\
\hline LI 10 & $498,52 \pm 37,55$ & $99,70 \pm 7,51$ & $151,16 \pm 12,21$ & $1,52 \pm 0,05$ \\
\hline LI 20 & $484,41 \pm 47,60$ & $96,88 \pm$ & $146,16 \pm 10,62$ & $1,51 \pm 0,06$ \\
\hline LI 30 & $485,73 \pm 41,29$ & $97,15 \pm$ & $144,44 \pm 16,77$ & $1,49 \pm 0,11$ \\
\hline AT 10 & $488,55 \pm 34,65$ & $97,71 \pm$ & $143,58 \pm 15,60$ & $1,47 \pm 0,10$ \\
\hline AT 20 & $486,78 \pm 18,18$ & $97,36 \pm 3,64$ & $141,48 \pm 4,93$ & $1,45 \pm 0,07$ \\
\hline AT 30 & $507,49 \pm 51,37$ & $101,50 \pm 10,27$ & $150,96 \pm 13,47$ & $1,49 \pm 0,06$ \\
\hline EX 10 & $525,36 \pm 46,35$ & $105,07 \pm 9,27$ & $161,52 \pm 20,11$ & $1,53 \pm 0,06$ \\
\hline EX 20 & $482,16 \pm 60,08$ & $96,43 \pm 12,02$ & $141,62 \pm 18,14$ & $1,47 \pm 0,06$ \\
\hline EX 30 & $484,76 \pm 52,93$ & $96,95 \pm 10,59$ & $139,72 \pm 18,08$ & $1,44 \pm 0,12$ \\
\hline
\end{tabular}

CAS = Dieta-padrão de caseína; $\mathrm{LI}=$ Levedura íntegra; $\mathrm{AT}=$ Autolisado $;$ Ex = Extrato

*Não houve diferença estatística significativa entre os grupos $(p \leq 0,05)$
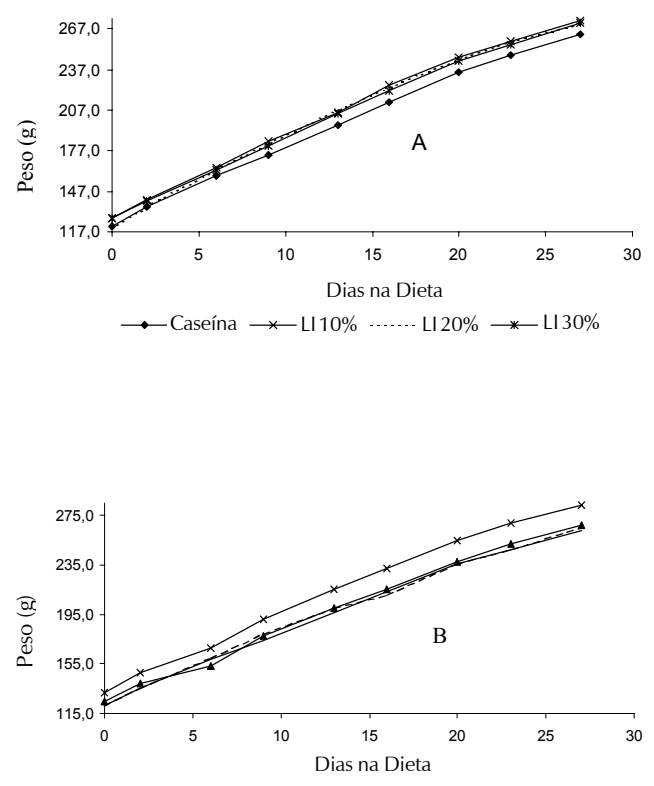

—Caseína ---- AT 10\% —-AT 20\% ——AT 30\%

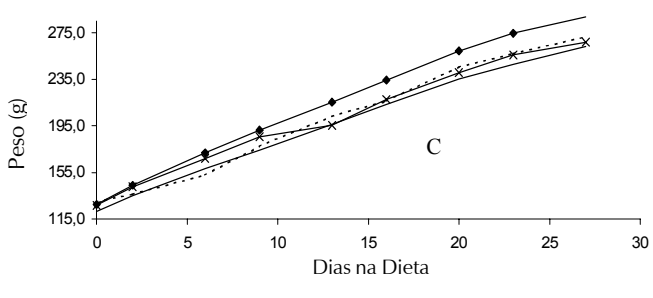

—Caseína —-EX10\% -....EX 20\% ——EX30\%

Figura 2. Curvas de crescimento para ratos recém-desmamados, mantidos em dieta-padrão (CAS 20\%) e dietas em que 10, 20 ou $30 \%$ da dieta de caseína foi substituída por misturas contendo, respectivamente, 4,8 , ou $12 \%$ de produto de levedura. A) levedura integra; B) autolisado; C) extrato.
Nota-se na Figura 2 (A, B, C) a evolução ponderal, no período de 4 semanas, para dietas com 10, 20 ou $30 \%$ de substituição da dieta-padrão de caseína, por misturas contendo aproximadamente 4, 8 ou 12\% de produtos de levedura. Apesar da não-significância estatística, as dietas contendo levedura, ou seus derivados, evidenciaram uma tendência de melhoria em função do aumento da concentração, particularmente do autolisado e do extrato de levedura. Como a dieta-padrão utilizada neste experimento é uma dieta nutricionalmente completa, indicada para ratos em crescimento, era de se esperar que houvesse uma perda de eficiência da dieta-padrão, com o aumento de introdução de produtos de levedura, em substituição à dieta-padrão. O comportamento inverso observado, ou seja, a tendência de aumento de eficiência da dieta com a substituição, sugere a existência de ação de um ou mais componentes funcionais específicos, particularmente no autolisado e no extrato de levedura.

Uma série de investigações têm demonstrado que componentes da levedura como nucleotídeos e derivados (Van Buren et al., 1983; Van Buren et al., 1985; Burmeiter \& Reinsford, 1991; Nair \& Ussery, 1992), polissacarídeos e oligossacarídeos (Chernysheva et al., 1991; Goldman \& Jaffe, 1991; Crittenden \& Playne, 1996) e peptídios bioativos (Mills et al., 1992), exercem ações fisiológicos muito importantes no organismo. Substâncias como nucleotídios e oligossacarídeos atuam como moduladores do sistema imunológico, estimulando o funcionamento tanto de células B como de células $T$, e neste sentido, aumenta a resistência dos organismos às infecções por bactérias e vírus. Os oligossacarídeos podem funcionar como prebióticos, propiciando o crescimento de microorganismos probióticos que inibem, no intestino, o desenvolvimento de bactérias patogênicas como Salmonella e Escherichia coli e, ao mesmo tempo, estimulam o desenvolvimento de bactérias lácticas e bactérias bífidas, benéficas ao organismo. Os nucleotídeos da dieta podem ainda acelerar a síntese de DNA nas células, auxiliando o 
crescimento e a recuperação de tecidos, principalmente em condições de estresse fisiológico (Nunes et al., 1990; Carver \& Walker, 1995). Um grande número de peptídios, originados na hidrólise das proteínas dos alimentos, apresentam atividades funcionais como imunoestimuladora, hipotensora, opióide, inibidora de bactérias patogênicas e facilitadora da absorção de certos nutrientes (Mills et al., 1992). Os autolisados e extratos de levedura contêm esses princípios ativos, em elevada concentração, portanto, é legítimo pensar que a ação combinada dos nucleotídeos, oligossacarídeos e peptídios ativos do autolisado e do extrato de levedura produziram um efeito sinérgico positivo e benéfico, ao se substituir parte da dieta-padrão por esses produtos. Como o maior nível de substituição (30\%) da dieta-padrão, com cerca de $12 \%$ de sólidos de levedura, produziu o melhor efeito de crescimento, é de se supor que concentrações maiores poderiam produzir efeitos ainda mais positivos.
Portanto, o efeito positivo observado na substituição de uma dieta balanceada, para o rato em crescimento, por derivados de levedura, mantendo-se a dieta modificada isoprotéica e isocalórica, deverá ser melhor estudada, para se determinar o nível de introdução de derivados de levedura capaz de produzir os melhores efeitos.

Verificou-se que após 15 dias de dieta não houve diferença estatística para o ácido úrico, entre os tratamentos, exceto para o Ex a $20 \%$ de substituição, que foi cerca de 3 vezes maior que para os demais tratamentos, sugerindo a possibilidade de erro experimental. Após 31 e 50 dias na dieta, apesar de ter havido diferenças estatísticas $(p \leq 0,05)$ entre alguns tratamentos, os valores ficaram muito próximos dos encontrados para a dieta-padrão (Tabela 3). Se for tomada como referência a faixa de variação 1,2 - 7,5 mg/dl), descrita para rato normal (Mitruka \& Rawnsley, 1981), conclui-se que os resultados encontrados estão todos dentro da faixa de normalidade.

Tabela 3. Níveis séricos de ácido úrico em ratos Wistar alimentados com dieta-padrão de caseína ( $20 \%$ de proteína) e dietas em que $10 \%$, $20 \%$ e $30 \%$ da dieta-padrão foi substituída por misturas contendo, respectivamente, 4, 8 ou 12\% de produto de levedura.

\begin{tabular}{|c|c|c|c|}
\hline \multirow{2}{*}{ Tratamentos } & \multicolumn{3}{|c|}{ Concentrações (mg/dl) } \\
\hline & 15 dias & 31 dias & 50 dias \\
\hline CAS (\%) & $1,68 \pm 0,23^{b}$ & $1,77 \pm 0,39^{\mathrm{bcd}}$ & $1,83 \pm 0,42^{\text {cd }}$ \\
\hline ப 10 & $2,03 \pm 0,47^{b}$ & $2,09 \pm 0,26^{\mathrm{ab}}$ & $1,84 \pm 0,47^{\mathrm{cd}}$ \\
\hline ப 20 & $1,68 \pm 0,31^{b}$ & $1,65 \pm 0,16^{\text {bcd }}$ & $5,59 \pm 0,71^{a}$ \\
\hline ப 30 & $1,85 \pm 0,33^{b}$ & $2,31 \pm 0,37^{a}$ & $1,61 \pm 0,19^{\text {cd }}$ \\
\hline AT 10 & $1,59 \pm 0,23^{b}$ & $2,07 \pm 0,48^{\mathrm{ab}}$ & $1,35 \pm 0,19^{d}$ \\
\hline AT 20 & $1,58 \pm 0,17^{b}$ & $1,73 \pm 0,16^{\text {bcd }}$ & $1,89 \pm 0,47^{\text {cd }}$ \\
\hline AT 30 & $1,61 \pm 0,11^{\mathrm{b}}$ & $1,39 \pm 0,81^{d}$ & $2,35 \pm 0,69^{b c}$ \\
\hline EX 10 & $1,62 \pm 0,23^{b}$ & $2,02 \pm 0,32^{\mathrm{abc}}$ & $2,93 \pm 0,26^{b}$ \\
\hline EX 20 & $5,90 \pm 0,38^{\mathrm{b}}$ & $1,52 \pm 0,27^{\text {cd }}$ & $1,98 \pm 0,14^{\text {cd }}$ \\
\hline EX 30 & $1,59 \pm 0,31^{b}$ & $1,43 \pm 0,13^{d}$ & $2,00 \pm 0,02^{\text {cd }}$ \\
\hline
\end{tabular}

${ }_{(\mathrm{a}, \mathrm{b}, \mathrm{c}, \mathrm{d})}$ Letras diferentes nas colunas indicam diferenças estatísticas $(\mathrm{p} \leq 0,05)$ entre tratamentos

Tabela 4. Níveis séricos de uréia em ratos Wistar submetidos à dieta-padrão de caseína (20\% de proteína) e dietas em que $10 \%$, 20\% e 30\% da dieta-padrão foi substituída por misturas contendo, respectivamente, 4, 8 ou 12\% de produto de levedura.

\begin{tabular}{|c|c|c|c|}
\hline \multirow{2}{*}{ Tratamentos } & \multicolumn{3}{|c|}{ Concentrações (mg/dl) } \\
\hline & 15 dias & 31 dias & 50 dias \\
\hline CAS $(\%)$ & $32,32 \pm 5,31^{\mathrm{bc}}$ & $52,47 \pm 2,78^{\mathrm{a}}$ & $46,09 \pm 7,57^{a}$ \\
\hline ப 10 & $39,24 \pm 9,27 \mathrm{abc}$ & $50,68 \pm 7,24^{a}$ & $43,95 \pm 2,67^{\mathrm{ab}}$ \\
\hline ப 20 & $35,51 \pm 6,20^{\mathrm{abc}}$ & $50,45 \pm 6,36^{a}$ & $45,57 \pm 2,55^{a}$ \\
\hline ப 30 & $43,17 \pm 4,60^{\mathrm{ab}}$ & $47,85 \pm 3,96^{\mathrm{a}}$ & $40,67 \pm 2,25^{\mathrm{abc}}$ \\
\hline AT 10 & $34,52 \pm 7,09^{b c}$ & $49,81 \pm 7,28^{\mathrm{a}}$ & $40,28 \pm 2,01^{\mathrm{abc}}$ \\
\hline AT 20 & $40,22 \pm 7,33^{\mathrm{abc}}$ & $45,66 \pm 7,91^{\mathrm{a}}$ & $40,75 \pm 2,44^{\mathrm{abc}}$ \\
\hline AT 30 & $29,64 \pm 1,58^{c}$ & $51,76 \pm 3,84^{\mathrm{a}}$ & $35,58 \pm 2,56^{c}$ \\
\hline EX 10 & $43,63 \pm 6,20^{\mathrm{ab}}$ & $49,76 \pm 5,43^{a}$ & $41,19 \pm 2,55^{\mathrm{abc}}$ \\
\hline EX 20 & $44,21 \pm 3,06^{a b}$ & $50,41 \pm 3,36^{\mathrm{a}}$ & $37,16 \pm 6,83^{\text {bc }}$ \\
\hline EX 30 & $48,20 \pm 11,79^{a}$ & $42,23 \pm 10,10^{a}$ & $40,92 \pm 2,74^{\mathrm{abc}}$ \\
\hline
\end{tabular}

$(a, b, c, d)$ Letras diferentes nas colunas indicam diferenças estatísticas $(p \leq 0,05)$ entre tratamentos 
Da mesma forma que para o ácido úrico, apenas em alguns casos foi constatada variação estatística, entre os tratamentos, para os níveis de uréia sangüínea. De um modo geral, as dietas contendo levedura não diferiram da dieta-padrão de caseína, com exceção da dieta com $30 \%$ de substituição (12\% de Ex) após 15 dias, com uma elevação de $40 \%$ em relação à caseína. Após 50 dias de tratamento, somente duas dietas (AT 30\% e Ex 20\%) apresentaram valores estatísticos diferentes, porém inferiores ao da dieta- padrão. Ao se observar os valores nos três intervalos de tempo (15, 31 e 50 dias), nota-se que após 15 dias nas dietas os valores absolutos de todos os tratamentos foram, em média, superiores ao da dieta-padrão, ao passo que depois de 31 e 50 dias os valores foram, em geral, mais baixos que os da dieta-padrão de caseína, sugerindo ter havido uma adaptação metabólica dos animais que receberam dietas contendo levedura (Tabela 4).

Após 15 dias nas dietas, os níveis de atividade de TGO não revelaram nenhum valor estatisticamente superior ao da dieta-padrão. A única dieta que apresentou diferença estatística em relação à padrão foi LI $20 \%$, aproximadamente $34 \%$ inferior. Diferenças estatísticas ocorreram entre alguns tratamentos com produtos de levedura nas dietas. De um modo geral, houve um aumento na atividade de TGO em função tempo. Níveis maiores de atividade foram registrados após 50 dias nas dietas, não tendo, entretanto, sido registradas diferenças entre tratamentos, com exceção de AT 10\% que apresentou um nível mais baixo de atividade (Tabela 5).

Tabela 5. Níveis séricos de atividade da transaminase glutâmico-oxalacética (TGO) em ratos Wistar submetidos a uma dieta-padrão de caseína ( $20 \%$ de proteína) e dietas em que $10 \%, 20 \%$ e $30 \%$ da dieta-padrão foi substituída por misturas contendo, respectivamente, 4,8 ou $12 \%$ de produto de levedura.

\begin{tabular}{|c|c|c|c|}
\hline \multirow{2}{*}{ Tratamentos } & \multicolumn{3}{|c|}{ Concentrações (mg/dl) } \\
\hline & 15 dias & 31 dias & 50 dias \\
\hline CAS (\%) & $112,85 \pm 11,96^{\mathrm{ab}}$ & $106,36 \pm 17,99^{a}$ & $127,93 \pm 9,07^{\mathrm{ab}}$ \\
\hline ப 10 & $83,38 \pm 16,08^{\mathrm{bc}}$ & $114,93 \pm 2,44^{a}$ & $39,01 \pm 9,68^{\mathrm{a}}$ \\
\hline ப 20 & $74,22 \pm 10,06^{c}$ & $103,12 \pm 11,08^{\mathrm{a}}$ & $138,76 \pm 11,03^{\mathrm{ab}}$ \\
\hline ப 30 & $97,00 \pm 19,36^{\mathrm{abc}}$ & $116,47 \pm 22,83^{a}$ & $132,23 \pm 15,53^{\mathrm{ab}}$ \\
\hline AT 10 & $89,65 \pm 19,26^{\mathrm{abc}}$ & $102,64 \pm 19,78^{a}$ & $120,82 \pm 9,16^{b}$ \\
\hline AT 20 & $119,24 \pm 22,98^{\mathrm{a}}$ & $93,80 \pm 15,25^{a}$ & $41,40 \quad \pm$ \\
\hline AT 30 & $82,74 \pm 14,49^{b c}$ & $106,95 \pm 6,96^{\mathrm{a}}$ & $142,56 \pm$ \\
\hline EX 10 & $86,78 \pm 11,36^{\mathrm{abc}}$ & $102,32 \pm 14,96^{a}$ & $142,56 \pm$ \\
\hline EX 20 & $93,38 \pm 21,05^{\mathrm{abc}}$ & $103,70 \pm 12,25^{a}$ & $131,07 \pm$ \\
\hline EX 30 & $89,87 \pm 7,23^{\mathrm{abc}}$ & $95,93 \pm 18,96^{a}$ & $131,89 \pm 4,58^{\mathrm{ab}}$ \\
\hline
\end{tabular}

${ }^{(a, b, c, d)}$ Letras diferentes nas colunas indicam diferenças estatísticas $(p \leq 0,05)$ entre tratamentos

Tabela 6. Níveis séricos de atividade da transaminase glutâmico-pirúvica (TGP) em ratos Wistar submetidos à dieta-padrão de caseína (20\% de proteína) e dietas em que $10 \%, 20 \%$ e $30 \%$ da dieta-padrão foi substituída por misturas contendo, respectivamente, 4, 8 ou 12\% de produto de levedura.

\begin{tabular}{|c|c|c|c|c|}
\hline \multirow{2}{*}{\multicolumn{2}{|c|}{ Tratamentos }} & \multicolumn{3}{|c|}{ Concentrações (mg/dl) } \\
\hline & & 15 dias & 31 dias & 50 dias \\
\hline & S $(\%)$ & $36,31 \pm 4,76^{b c}$ & $58,91 \pm 14,64^{a}$ & $38,89 \pm 7,73^{c}$ \\
\hline$\sqcup$ & 10 & $40,75 \pm 0,07^{b c}$ & $49,50 \pm 5,34^{a}$ & $42,30 \pm 2,86^{\mathrm{abc}}$ \\
\hline$\sqcup$ & 20 & $26,51 \pm 6,48^{\mathrm{d}}$ & $47,87 \pm 8,02^{\mathrm{a}}$ & $46,79 \pm 3,83^{\mathrm{abc}}$ \\
\hline$\sqcup$ & 30 & $35,49 \pm 1,55^{\mathrm{abc}}$ & $55,19 \pm 8,73^{a}$ & $45,21 \pm 7,83^{\mathrm{abc}}$ \\
\hline AT & 10 & $18,93 \pm 4,31^{\mathrm{d}}$ & $51,79 \pm 8,57^{a}$ & $39,59 \pm 1,53^{\mathrm{bc}}$ \\
\hline AT & 20 & $75,24 \pm 18,72^{\mathrm{a}}$ & $45,32 \pm 3,48^{\mathrm{a}}$ & $51,59 \pm 2,87^{a}$ \\
\hline AT & 30 & $44,54 \pm 7,67^{b}$ & $46,24 \pm 10,78^{\mathrm{a}}$ & $49,19 \pm 3,92^{\mathrm{a}}$ \\
\hline EX & 10 & $35,88 \pm 1,77^{\mathrm{bc}}$ & $45,65 \pm 4,35^{a}$ & $48,24 \pm 7,33^{\mathrm{ab}}$ \\
\hline EX & 20 & $38,14 \pm 4,05^{\mathrm{bc}}$ & $45,65 \pm 3,30^{\mathrm{a}}$ & $42,30 \pm 3,50^{\mathrm{abc}}$ \\
\hline EX & 30 & $45,32 \pm 6,31^{b}$ & $46,92 \pm 7,92^{\mathrm{a}}$ & $47,93 \pm 1,39^{\mathrm{abc}}$ \\
\hline
\end{tabular}

$(a, b, c, d)$ Letras diferentes nas colunas indicam diferenças estatísticas $(p \leq 0,05)$ entre tratamentos 
Com relação à TGP, os resultados (Tabela 6) seguiram tendência muito semelhante à TGO. Após 15 dias na dieta, dois resultados diferiram estatisticamente ( $p \leq 0,05)$ da dieta-padrão, AT 20\% que foi praticamente o dobro e AT $10 \%$ que foi inferior. Todos os demais tratamentos não diferiram estatisticamente da dieta-padrão. Após 31 dias não se registrou diferença estatística entre os tratamentos. Após 50 dias, apenas os resultados das dietas AT $20 \%$, AT $30 \%$ e Ex $10 \%$ foram estatisticamente superiores ao da dieta-padrão.

De acordo com Lima et al. (1985), a TGP ocorre nos hepatócitos em concentrações mais elevadas que a TGO. Portanto, a atividade de TGP no soro sangüíneo poderá ter maior significado clínico que a TGO, como diagnóstico de lesão hepática.

Como os valores de atividade sérica para TGO e TGP, na maioria dos tratamentos que receberam produtos de levedura na dieta, não ultrapassaram o valor encontrado para a dieta-padrão de caseína, conclui-se não ter havido injúria do tecido hepático, nos animais que receberam dietas com produtos de levedura. Da mesma forma, como os níveis séricos de uréia nas dietas experimentais não ultrapassaram os níveis registrados para a dieta-padrão de caseína, conclui-se que a presença de produtos de levedura nas dietas experimentais não deve ter afetado a função renal.

\section{CONCLUSÃO}

Substituição da dieta-padrão AIN-93G, nos níveis de 10,20 e $30 \%$, por uma mistura isoprotéica e isocalórica, contendo respectivamente 4,8 e $12 \%$ de produtos de levedura não afetou a ingestão de dieta, o ganho de peso e o ganho de peso por unidade de proteína ingerida $\left(\mathrm{PER}_{\mathrm{op}}\right)$. Embora não tenha havido diferença estatística, os animais em dietas com autolisado ou extrato de levedura, evidenciaram uma tendência de maior ganho de peso, acentuada com o aumento da concentração dos derivados de levedura. Embora se tenha registrado algumas variações nos índices séricos de ácido úrico, uréia e atividade das transaminases (TGO e TGP) entre alguns tratamentos contendo produtos de levedura, esses índices, na maioria, foram iguais ou inferiores aos encontrados para a dieta-padrão de caseína, permitindo concluir não ter havido lesões hepáticas e/ou renais em virtude da ingestão das dietas contendo produtos de levedura.

\section{AGRADECIMENTOS}

Os autores agradecem à FAPESP (Fundação de Amparo à Pesquisa do Estado de São Paulo) pelo suporte financeiro para esta pesquisa.

\section{REFERÊNCIAS BIBLIOGRÁFICAS}

ALIAN, A., EL-AKHER, M.A., ABDOU, I., AID, N. Enrichment of local bread with dried brewery yeast. I. Chemical and biological evaluation of dried brewery yeast and flour. Egyptian Journal of Food Science, Cayro, v.11, n.1/2, p.23, 1983a.

ALIAN, A., EL-AKHER, M.A., ABDOU, I., AID, N. Enrichment of local bread with dried brewery yeast. II. Physical properties of dough and biological and sensory evaluation of bread. Egyptian Journal of Food Science, Cayro, v.11, n.1/2, p.31, 1983b.

ANON. Autolyzed yeast enhance flavours in low sodium foods. Food Development, Chicago, v.15, n.9, p.52, 1981.

ASSOCIATION OF OFFICIAL ANALYTICAL CHEMISTS. Official methods of analysis. 15.ed. Arlington, 1990. v.2.

ASP, N., JOHANSSON, C.G., HALMER, H., SILJESTRÖM, M. A rapid enzymatic assay of insoluble and soluble dietary fiber. Journal of Agricultural and Food Chemistry, Easton, v.31, n.3, p.476-482, 1983.

BELEM, M.A.F., LEE, B.H. Production of RNA derivatives by Kluyveromyces marxianus grown on whey. Food Science and Technology International, London, v.3, n.6, p.437-444, 1997.

BELEM, M.A.F., LEE, B.H. Production of bioingredients from Kluyveromyces marxianus grown on whey: an alternative. Critical Reviews in Food Science and Nutrition, Cleveland, v.38, n.7, p.565-598, 1998.

BLIGH, E.G., DYER, W.J. A rapid method of total lipid extraction and purification. Canadian Journal of Biochemistry and Physiology, Ottawa, v.37, p.911-917, 1959.

BOSTIAN, M., SMITH, N., GILLIARD, S.E., STEWART, C.F. Snack foods provide natural target for supplementation with yeast-whey protein. Food Product Development, Chicago, v.12, n.9, p.68-70, 1978.

BURMEITER, G., RAINSFORD, K.D. Discrimitating effects of a nucleotide-rich extract probioticum, as an immunomodulator contrasted with actions in chronic immuno-inflammatory disease (adjuvant-induced arthritis) in rodents. Inflammopharmacology, Dordrecht, v.1, p.161-183, 1991.

CAMERON, D.R., COOPER, D.G., NEUFELD, R.J. The mannoprotein of Saccharomyces cerevisiae is an effective bioemulsifier. Applied and Environmental Microbiology, Washington DC, v.54, n.6, p.1420-1425, 1988.

CARVER, J.D., WALKER, W.A. The role of nucleotides in human nutrition. Journal of Nutritional Biochemistry, Stoneham, v.6, n.2, p.58-72, 1995.

CHERNYSHEVA, N.M., KAPLAN, V.P., KONOPLYANNIKOV, A.G., BABAYAN, T.L., LEPEKHINA, L.A. The stimulatory granulocyte-macrophage graftment and the radioprotective effect of yeast mannan. Radiobiologiya, Moscow, v.31, n.3, p.381-386, 1991.

CHING-MING, L.J., CHASTAIN, M.F., STRENGTH, D.R. Sensory and nutritional evaluation of wheat bread supplement with single cell protein from Torula yeast (Candida utilis). Journal of Food Science, Chicago, v.51, n.3, p.647-652, 1986.

CRITTENDEN, R.G., PLAYNE, M.J. Production properties and applications of food grade oligosaccharides. Trends in Food Science and Technology, Cambridge, v.7, n.11, p.353-361, 1996. 
DZIEZAK, J.D. Yeast and yeast derivatives: definitions, characteristics, and processing. Food Technology, Chicago, v.41, n.2, p.104-121, 1987.

GOLDMAN, R., JAFFE, C.L. Administration of $\beta$-glucan following Leishmania major infeccion suppresses disease progression in mice. Parasite Immunology, Oxford, v.13, n.2, p.137-146, 1991.

GUZMÁN-JUAREZ, M. Development in food proteins. London : Applied Science Publishers, 1983. 339p.

HALÁSZ, A. Biochemical principles of the use of yeast biomass in food production. Budapest, 1988. Thesis (Doctorate)Hungarian Academy of Sciences, 1988. (Abstract).

HALÁSZ, A., LÁSZTITY, R. Use of yeast biomass in food production. Boca Raton : CRC Press, 1991. p.312.

HEBERT, D., PHIPPS, P.J., STRANGER, R.E. Chemical analysis of microbial cells. In: NORIS, J.R., RIBBORS, P.W. (Ed.). Methods of enzymology. London : Academic Press, 1971. v.5B.

JUNILLA, M., KOIVURINTA, J., KURKELA, R., KOIVISTOINEN, $P$. Functional properties of brewer's grain, brewer's yeast and distillers stillage in food systems. II. Application to sausages and meat balls. Fleischwirtschaft, v.6, n.7, p.1024-1049, 1981.

KAMEL, B., KRAMER, A., SHEPHARD, A.J., NEUKIRK, D.R. Amino acid, fatty acid, cholesterol and other sterols analysis of different pizza formulations. Journal of Food Quality, Westport, v.2, n.2, p.123, 1979.

KOLLAR, R., STURDIK, E., SAJBIDOR, J. Complete fractionation of Saccharomyces cerevisiae biomass. Food Biotechnology, New York, v.6, n.3, p.225-237, 1992.

LÁSZTITY, R. Sofia: Cryobiological aspects of long term storage of meats and changes of their quality. In: TSVETKOV, T. (ed.). Cryobiology Freeze-Drying. [s.I.], 1987. 199p. Proceedings of the Third National School in Cryobiology of Freeze-Drying, 9. (Central Problem Laboratory of Cryobiology and Freeze-Drying)

LIMA, A.O., SOARES, J.B., GRECO, J.B., GALIZZAI, J., CANCADO, J.R. Métodos de laboratório aplicados à clínica: técnica e interpretações, 6.ed. Rio de Janeiro : Guanabara Koogan, 1985. p.699.

McCORMICK, R.D. Improved flour and nutritional enhancement for pasta products. Food Product Development, Chicago, v.9, n.6, p.11, 1975.

MILLS, E.N.C., ALCOCER, M.J.C., MORGAN, M.R.A. Biochemical interaction of food derived peptides. Trends in Food Science and Technology, Cambridge, v.3, n.3, p.64-68, 1992.

MITRUKA, M.B., RAWNSLEY, H.M. Clinical, biochemical and hematological reference values in normal experimental animals and normal humans. 2.ed. New York : Masson Publishing, 1981. p.314.
NAIR, V., USSERY, M.A. New hypoxanthine nucleosides with RNA antiviral activity. Antiviral Research, Amsterdam, v.19, n.2, p.173-178, 1992.

NUNES, M.C., AYUDARTE, M.V., MORALES, D., SUAREZ, M.D., GIL, A. Effect of dietary nucleotides on intestinal repair in rats with chronic diarrhea. Journal of Parenteral and Enteral Nutrition, Baltimore, v.14, n.2, p.598-604, 1990.

PACHECO, M.T.B., CABALLERO-CÓRDOBA, G.M., SGARBIERI, V.C. Composition and nutritive value of yeast biomass and yeast protein concentrates. Journal of Nutritional Sciences and Vitaminology, Tokyo, v.43, n.6, p.601-612, 1997.

PARKS, L.L., CARPENTER, J.A., REAGAN, J.O. Effects of an autolysed yeast on physical and sensory properties of frankfurters. Journal of Food Quality, Westport, v.9, n.4, p.225-229, 1986.

REEVES, P.G., NIELSEN, F.H., FAHEY Jr., G.C. AIN-93 purified diets for laboratory Rodents: final report of the American Institute of Nutrition ad hoc committee on the reformulation of the AIN-76 a Rodent diet. Journal of Nutrition, Bethesda, v.123, n.2, p.467-472, 1993.

SCHACKELFORD, J.R., MURRAY, D.G. Studies show no shelf-life loss from usual food yeasts in products. Food Product Development, Chicago, v.14, n.9, p.40, 1980.

SCHMIDT, G. Bubbling over with yeast. Food, Flavouring, Ingredients, Packaging and Processing, London, v.9, n.5, p.25, 1987.

SGARBIERI, V.C. Proteínas em alimentos protéicos: propriedades, degradações, modificações. São Paulo : Varela, 1996. p.374.

SOMMER, R.A. Yeast autolysates as flavor enhancers in prepared meals and meat products. Lebensmitteltechnik, Hamburg, v.15, n.5, p.229, 1983.

STACTISTICA for Windows: computer program manual. Tulsa : STATSOFT, 1995. 27p.

STEWART, C.F., GILLIAND, S.E. Utilizing yeast-whey protein to improve the nutritional value of snack foods. American Dairy Review, v.41, n.4, Supplement A30, 1979.

VAN BUREN, C.T., KULKARNI, A.D., SCHANDLE, V.B., RUDOLPH, F.R. The influence of dietary nucleotides on cell-mediated immunity. Transplantation, Baltimore, v.36, n.3, p.350-352, 1983.

VAN BUREN, C.T., KULKARNI, A.D., FANSLOW, W.C., RUDOLPH, F.R. Dietary nucleotides, a requirement for helper/inducer T lymphocytes. Transplantation, Baltimore, v.40, n.6, p.694-697, 1985.

Recebido para publicação em 14 de maio e aceito em 1 de setembro de 1999. 